\title{
HUSSAIN FAIZHANOV'S IDEAS ON REFORMING THE MUSLIM EDUCATION AS A SIGN OF TIME
}

\author{
Nadezhda Vasilyevna Kostenyuk \\ Director, Museum \\ of Nizhny Novgorod State Linguistics University named after N.A. Dobrolyubov \\ nkudrash@mail.ru \\ Minina St., 31a, 603155 Nizhny Novgorod, Russian Federation
}

\begin{abstract}
The author analyses the activity of such a bright personality as H. Faizhanov - an outstanding Tatar public figure, teacher, historian, orientalist-turcologist, specialist in the study of early texts, calligrapher that came from Nizhny Novgorod Tatar community. The object of the present research is the project of educational reform that was planned by the scientist for its realization in Tatar-Mussulmen environment. The materials of the article show that the author of the project - H. Faizhanov - reveals himself as a Russian scientist and educator, coming ahead of his time and persuading his contemporaries in the necessity of the reformation of Muslim education. Failed to be realized, the Faizhanov's project exerted a great influence on the next educational practices of Russian society and stimulated Muslim Tatars' school reforms that were later manifested in the development of a new education method (that was called "usul-dzhadid" - dzhadidizm). Furthermore, the author puts forward the problem of combination of Faizhanov's ideas with new elements of imperial politics towards so-called "non-Russians". The scientific novelty of this article is that the author treats the activity of H. Faizhanov as the fact of expression of forming tendencies of the middle of the the 19th centure, notably - the unification of Russian people of ethnicity and confession.
\end{abstract}

Key words: ethnos, confession, personality, Nizhny Novgorod Tatars, Russian society, education.

УДК 39:94(470)“18”

Дата поступления статьи: 12.01.2016

ББК 63.3(2)5

\section{ИДЕИ РЕФОРМИРОВАНИЯ МУСУЛЬМАНСКОГО ОБРАЗОВАНИЯ ХУСАИНА ФАИЗХАНОВА КАК ЗНАК ВРЕМЕНИ}

\section{Надежда Васильевна Костенюк}

\begin{abstract}
Директор музея,
\end{abstract}
Нижегородский государственный лингвистический университет им. Н.А. Добролюбова nkudrash@mail.ru

ул. Минина, 31a, 603155 г. Нижний Новгород, Российская Федерация

\footnotetext{
Аннотация. В статье анализируется деятельность яркой личности Х. Фаизханова (1823-1866), видного татарского общественного деятеля, преподавателя, историка, востоковеда-тюрколога, археографа, каллиграфа, вышедшего из нижегородской татарской среды. Объектом внимания автора статьи является проект образовательной реформы, намеченной ученым для реализации в среде татар-мусульман. Материалы ㄱ. статьи показывают, что автор проекта Х. Фаизханов раскрывается как российский ученый и просветитель, опережающий свое время, убеждающий современников в необходимости реформирования мусульманского образования. Так и нереализованный фаизхановский проект оказал большое влияние на последующие образовательные практики российского общества, подтолкнув татар-мусульман к обновлению школьного дела, выразившегося в развитии новометодного образования (получившего название «усуль-джадид» - джадидизм). В статье ставится проблема сочетания идей Х. Фаизханова с новыми элементами () имперской политики по отношению к так называемым «инородцам». Научная новизна данной статьи
} 
заключается в том, что автор впервые рассматривает деятельность Х. Фаизханова как факт выражения вызревающих тенденций того времени, а именно сближения людей российского общества разной этнической и конфессиональной принадлежности.

Ключевые слова: этнос, конфессия, личность, нижегородские татары, российское общество, образование.

Цель автора статьи - обратить более пристальное внимание исследователей на проблему роли личности в истории, что само по себе важно и значимо для развития исторической науки. Но посмотреть на эту проблему, достаточно основательно и давно обсуждаемую историософами [2, с. 300-304], предлагается по-новому, увязав мотивацию деятельности отдельной персоны, характер и результаты ее труда с потребностью совершенствования этноконфессиональных взаимодействий, которое в определенный момент осознается обществом или гениально улавливается отдельными его представителями.

В этом новом подходе к пониманию проблемы личности в истории и заключается научная новизна данной статьи. Выбор личности актуализирован и неординарностью самой личности, и особым интересом современного общества к исследованию этноконфессиональных взаимодействий.

Интерес к Х. Фаизханову резко возрос на рубеже XX-XXI вв., когда по инициативе Духовного управления мусульман Нижегородской области был написан и опубликован ряд научных трудов о жизни и деятельности ученого [6; 11], а также изданы некоторые из его научных произведений [8; 10; 12]. С 2004 г. начали действовать (и действуют до сего дня) ежегодно проводимые Фаизхановские чтения - научная конференция, 10-летний юбилей которой прошел в 2014 г. в рамках Международного мусульманского форума в Москве [3]. Интерес ученых и публицистов к личности Фаизханова сохраняется и в наши дни. В ходе XII Международной научно-образовательной конференции «Фаизхановские чтения» на тему: «Мечеть как центр единения уммы, образовательной и социальной работы» (г. Нижний Новгород, 27-29 августа) был осуществлен показ документального фильма «Два крыла», созданного в рамках проекта «Мусульмане, которыми гордится Россия», посвященного Х. Фаизханову.

Нижегородчина, откуда вышел этот видный представитель татарского просвещения - центр Восточно-Европейской равнины и вместе с тем стыковой регион в природно-географическом, этническом, конфессиональном смыслах. Особенности развития региона, имеющего единое территориальное управление, неизбежно диктовали сближение людей, разделенных по этническим и религиозным признакам, но вместе с тем объединенных политической силой в лице государства $[5 ; 7]$.

Взаимные представления друг о друге складывались столетиями. Рано или поздно нижегородские татары должны были включиться в процессы активных взаимодействий, подготовленные рядом поколений людей, представляющих разные этносы и конфессии, но, тем не менее, живущих бок о бок, мирно, по-добрососедски.

Выстраивание вертикали все более усиливавшейся государственной власти создавало особые условия существования этносов в регионе. На протяжении длительного времени в сфере этноконфессиональных взаимодействий доминировало влияние государства. Еще в XVIII в. оно приобрело ярко выраженный имперский характер. Русское православное население в XIX в. численно преобладало на Нижегородчине, и ему уделялось значительное внимание, но, укрепляя вертикаль власти и желая сохранить целостность многоэтничной империи, политический центр заботился и о неславянском населении отдельного региона с преобладающим православным составом проживающих в нем людей.

Нижегородских татар, издавна населявших лесостепной юго-восток Нижегородчины и сохранявших особенности сельской культуры, отличала традиционность стиля жизни, добрые отношения с соседями: русскими, мордвой, мари и чувашами. Территориальное ядро проживания татар представляло собой совокупность компактно расположенных селений. Татары сохраняли мусульманскую веру, всячески оберегая ее от какого-либо влияния извне.

«Мусульмане-татары, будучи гражданами России и одним из народов нашей Родины 
России, - писал X. Фаизханов, - признают Россию своей Родиной и царя своим кормильцем и повелителем, русских своими соотечественниками, друзьями и соседями, с которыми неразлучно сплочены» [8, с. 164]. Государство не препятствовало мусульманским практикам: «Российское государство настолько милостиво к мусульманам, что оно уравняло мусульман с русскими во всех правах, без исключения» [8, с.169]. Но равенство подданных империи не означало, по его мнению, что российские татары должны потерять свою культуру, напротив, «каждому человеку дороги своя религия и нация» [8, с. 170].

Хусаин Фаизханов (1823-1866) - уроженец татарского села Сафаджай (ныне Красная Горка Пильнинского района Нижегородской области), носитель ценностных установок многоэтничной российской цивилизации, человек, испытывавший на себе влиянием процессов, которые были характерны для российской жизни середины XIX столетия. Сам он, получивший основы мусульманского образования в местном медресе в Сафаджае, а затем углубивший знание вероучения в Казани, вышел за рамки богословия и стал преподавателем одного из лучших университетов страны - Санкт-Петербургского университета, тогда центра российского востоковедения.

Специалист в области тюркологии, лингвист, историк, каллиграф, просветитель, Хусаин Фаизханов еще в середине XIX столетия впервые показал образец общения татарского ученого с представителями российской полиэтничной культуры. Такое утверждение можно сделать, вспомнив состав востоковедов Санкт-Петербургского университета во время работы там преподавателя (адъюнкта) Фаизханова. Он оказался в Санкт-Петербурге после перевода из Казани Восточного факультета Казанского университета в столичный университет.

В 1858 г., когда на Восточный факультет университета пришел Хусаин Фаизханов, среди профессоров этого факультета значились А.К. Казембек, возглавлявший кафедру арабско-персидской словесности и являвшийся деканом факультета; ординарный профессор той же кафедры шейх ат-Тантави и ординарный профессор турецкой кафедры А.О. Мухлинский $[13$, с. 11]. В коллективе факультета работал и ученый-сириец Селим Нофаль, автор трудов по мусульманскому праву. Даже сам по себе достаточно пестрый состав коллектива позволял расширять кругозор татарина из глубинки и подталкивать его к расширению кругозора.

Хусаин Фаизханов, воспитанный и образованный в рамках традиций татар-мусульман российской глубинки, стал человеком, которого целиком захватили такие сферы жизнедеятельности, как наука и образование [9, с. 6690]. Он сумел заглянуть в будущее и понял, что специфика жизни российского мусульманина - в том окружении, в котором он находится, и это окружение многоэтнично. Причем это окружение сложилось не искусственно, а вполне естественно, исторически. Даже если бы нашелся такой мусульманин, которому хотелось бы жить в исламском государстве среди единоверцев, он не мог бы изменить объективно сложившуюся в российском обществе ситуацию многоконфессиональности, оставаясь на Родине.

Хусаин Фаизханов понял бесперспективность замкнутости отдельных монорелигиозных по составу населения деревень в условиях того российского общества, которое приближалось к единому капиталистическому рынку. Поскольку Хусаин был патриотом своего татарского народа, гордился его культурой, достижениями, его устремления оказались направленными в сторону улучшения образования татар.

Проект реформы мусульманского образования Хусаин Фаизханов изложил в своем труде под названием «Ислах мадарис». Эта работа для русскоязычного читателя стала доступна только в XXI столетии [10].

Уже в самом начале своей книги автор сетовал на то, что татары по сравнению с русскими людьми не двигаются по пути прогресca, не приобретают необходимые им для жизни в многоэтничном обществе знания. Он пытался разобраться, что же мешает татарам развиваться, чтобы не отставать от русских. Относясь с большим уважением к своему народу и его религии - исламу, Х. Фаизханов подчеркивает, что мусульмане в прошлые средневековые времена достигли очень высокого уровня культуры. Ислам не только не запрещал им получать знания, но и всячес- 
ки способствовал тому, чтобы последователи Аллаха постоянно совершенствовали их.

Поставив вопрос, что же мешает татарам-мусульманам середины XIX в. продвигаться вперед в сфере образования, Х. Фаизханов утверждает следующее: «Некоторые думают, что ислам запрещает мусульманам получать образование. Это безосновательное утверждение, поскольку более всех религий ислам повелевает приобретать знание и образование» [12, с. 19] - и далее обосновывает это утверждение ссылками на Коран и Хадисы. Исходя из собственной логики рассуждений, отринув религию как тормоз получения знаний, он искал другие причины пренебрежения татар-мусульман к наукам. В связи с этим он восклицает: «Значит, Российское государство им и их соотечественникам запрещает развиваться в области образования?». И тут же сам отвечает на поставленный вопрос: «Не дай бог, и этого нет... Российское государство не только не препятствовало этому, напротив, давало безграничные разрешения» [12, с. 21].

Продолжая рассуждать о причинах «плохого состояния дел», Х. Фаизханов высказывает интересные соображения, касающиеся психологии поведения своих «соплеменников». Эти мысли напрямую связаны с интересующим нас сюжетом этноконфессиональных взаимодействий татар-мусульман и русских-православных. «Какой-нибудь русский, - вопрошает Х. Фаизханов, - отдаст своего ребенка в возрасте 10-12 лет в татарское медресе? Если у этого ребенка внешний вид, одежда, манеры, характер и мысли будут татарскими, короче, если в душе он будет татарином! Конечно, с этим мало кто согласится. Особенно необразованный народ будет против этого» [12, с. 22]. Кроме того, автор указывает на особенности поведения подростков: находясь в русской среде, они будут стесняться «исполнять правила религии». К варианту совместного обучения детей разной этнической принадлежности татары тогда были явно не готовы. Известные факты неприятия такой формы обучения со стороны татар при внедрении впоследствии русско-татарских школ подтверждают правильность рассуждения X. Фаизханова.

Итак, причины плохого состояния дел в сфере образования Хусаин Фаизханов видит в невежестве простых людей и невозможнос- ти их в связи с этим глубоко понимать нормы шариата: «...татары не отдают детей в учебные заведения, открытые царем, и согласны оставаться в невежестве ради сохранения своей религии» $[12$, с. 23].

Что же предлагал ученый? Он выдвинул компромиссную идею создания специальных медресе. В них на татарском языке, родном для учащихся шакирдов, могло бы происходить обучение мусульманской юриспруденции и арабской филологии. На русском языке преподаватели должны были донести до обучаемых знания европейских языков, географии, медицины и естествознания.

Таким образом, он выступал за изучение татарами русского языка, а через русский язык за ознакомление со светскими науками. Не ограничиваясь призывом постигать культуру русского народа, он считал необходимым овладение татарами культурой европейского мира. Понимая, что ислам сохраняет татарский этнос от размывания и исчезновения, $\mathrm{X}$. Фаизханов всегда помнил о значении религии в деле развития его родного народа. Основная идея Хусаина Фаизханова, касающаяся сферы образования, - необходимость получения не только религиозного знания, но и знания светского, что вызывало неприятие даже некоторых его односельчан, опасавшихся русификации. В этом своем убеждении он опередил тех мыслителей и просветителей, которые с конца XIX в. получили наименование джадидов, обновленцев. По его мнению, татары, не теряя мусульманского стиля жизни, родного языка, обычаев и традиций, неизбежно должны вливаться в общекультурные процессы. Тяга к знаниям, присущая Хусаину Фаизханову, позволила ему не только создать концепцию этногенеза татарского народа, но и увязать татарскую историю с другими этническими историями (чувашской, финской, мордовской и др.).

Его активная деятельность приходится на период интенсивного проведения реформ либерального характера, Великих реформ, начатых с отмены крепостного права. Необходимость перемен осознавалась в обществе все активнее в условиях формировании нового социального слоя интеллигенции. Общественное сознание подогревалось в этом направлении газетами и журналами. Импера- 
тор Александр II и политическая элита того времени «дали добро» на трансформацию жизни подданных. Тем не менее общественному сознанию середины века была свойственна противоречивость. С одной стороны, как было сказано, созревали перемены, направленные на либерализацию общественной жизни. С другой-именно тогда, в 1860-егт., Россия, претендуя на влияние в европейских делах, так же как и Западная Европа, стала придавать особое значение идее государственного единства, достижение которого осложнялось полиэтничностью и поликонфессиональностью общества, составляющие которого (этноконфессиональные общности) стремились ко все большей самоидентификации. Позднее русификаторская политика времен Александра III будет вызывать все большее отторжение. Согласно сформулированному в 1860-х гг. влиятельным публицистом М.Н. Катковым определению, России было необходимо единое и сильное государство. Идеал «единой и неделимой» России стал со второй половины XIX в. основным ориентиром имперской политики.

Но Х. Фаизханов жил в то время, когда еще не оформился так называемый «мусульманский вопрос», пугающий власть. Это произойдет позже. В то время российские мусульмане не были объектом опасений власти, как это будет в начале XX века.

Почему мы говорим об определенном опережении времени X. Фаизхановым в его проекте реформы мусульманского образования? В то время, когда ученый работал (середина века), тюрко-мусульманское население России еще не чувствовало в полной мере тех модернизационных процессов, которые охватят страну в дальнейшем. Еще не стал доминирующим принцип государственного единства России, не было ярко выраженных тенденций реализации идеи национального государства. Эта идея так и не стала государственной идеей даже при Александре III. Но чувствуя возможные перемены, X. Фаизханов ищет пути повышения уровня образования своего народа, используя потенциал ученого. К тому же подчеркнем, что в 1860-х гг. только начинала формироваться правовая основа школьного дела в среде татар-мусульман. Делались первые шаги в этом направлении.
В 1866 г. министр народного просвещения Д.А. Толстой отметит, посещая учебные заведения Казанского учебного округа: «...инородцы обитают в большом числе почти во всех губерниях в том же невежестве, в котором находились несколько столетий тому назад, и при том в отчужденности от русского элемента» [цит. по: 4, с. 13]. Но Хусаин Фаизханов об этих оценках уже не узнает. Не узнает он и о том, что 26 марта 1870 г. Александром II будут утверждены «Правила о мерах к образованию населяющих Россию инородщев», которые фактически положат начало имперским попыткам ассимиляции татар-мусульман. Ассимиляция понималась как осуществляемая через распространение русского языка. Еще раз вспомним, что Х. Фаизханов не был противником приобщения татар к русскому языку и в целом к русской культуре, но при сохранении знания и любви к культуре татарского народа. Власти в указанном документе, по сути, не обращаясь к идеям ученого, тем не менее, делали шаги к сближению народов, констатируя, что русский язык должен войти в образование татар через учреждение начальных сельских и городских русско-татарских училищ. Отсутствие должного количества учителей, способных преподавать татарам русский язык, могло привести к активизации этнокофессиональных взаимодействий (русские - татары, православные - мусульмане) в рамках планируемых учебных заведений. Образование, полученное таким образом, могло служить основой для дальнейшего сближения русских и татар. Например, при поступлении окончивших эти начальные учебные заведения в образовательные учреждения среднего и далее высшего звена.

На основании сказанного можно утверждать, что Х. Фаизханов со своим проектом образовательной реформы опередил время, заглянул в будущее перемен в российском образовательном поле. Он предугадал в некоторой степени движения по реализации имперского проекта сближения этносов как подданных «единой и неделимой России», хотя и не мог предположить, что будет реализовываться политика русификации.

Но разработка Х. Фаизхановым проекта реформы образования мусульман задумывалась им не с целью уничтожения татаро- 
мусульманской идентичности, а с благими намерениями повысить значение своего народа в мировой истории. Он писал о необходимости направления усилий всех представителей татар на повышение уровня образованности, а особенно тех татар, которые имеют высокие материальные возможности.

Он сетует, что имеющиеся перемены, развернувшиеся реформы, в частности земскую реформу, татары не замечают и не хотят использовать в своих целях.

Образ такого человека, как Х. Фаизханов, востребован в современном российском обществе. Широкие знания об окружающем мире, постоянное их совершенствование, непризнание крайностей национализма, честность, порядочность, скромность, огромноетрудолюбие, стремление к обновлению жизни родного татарского народа и приобщению его к высшим достижениям научного знания - все это было присуще Хусаину Фаизханову.

$\mathrm{X}$. Фаизханов жил в условиях активизации отношений этноконфессионального характера в силу действия ряда факторов, приоритетным из которых на то время может быть назван социально-экономический фактор: Россия двигалась в капитализм. Но не только в социально-экономических движениях того времени были заложены тенденции к усилению коммуникативного общения разных этносов и конфессий.

Поэтому вызревала потребность в персонификации процесса усиления взаимодействий этносов. Рождались такие люди, как Фаизханов. Х. Фаизханов, сотрудничавший с русскими и представителями других этносов России, непонятый многими представителями своей этнической среды, оказался, тем не менее, предвестником тесного сближения разных этносов российского сообщества, которое вскоре стало вполне очевидным.

Высокий уровень развития интеллектуальной элиты в российском обществе, имеющаяся в ней достаточно выраженная этническая толерантность создали объективные предпосылки для возможной деятельности Х. Фаизханова как ученого и просветителя.

Своими мыслями и научными трудами $\mathrm{X}$. Фаизханов отражал назревавшие в российском обществе тенденции усиления этноконфессиональных взаимодействий горизонтального уровня.

\section{СПИСОК ЛИТЕРАТУРЫ}

1. Мухетдинов, Д. В. Хусаин Фаизханов - классик татарского просвещения, истории и педагогики / Д. В. Мухетдинов - Москва ; Нижний Новгород : Медина, 2014. -340 с.

2. Плеханов, Г. В. К вопросу о роли личности в истории / Г. В. Плеханов // Избранные философские произведения. В 5 т. Т. ІІ. - М. : Гос. изд-во полит. лит., 1956. -824 с.

3. Реформы образования мусульман Евразии от Хусаина Фаизханова до Исмаила Гаспринского: исторический опыт и современная актуальность. // Материалы Юбилейной X Всерос. науч.практ. конф. с междунар. участием «Фаизхановские чтения» (Москва, 12 дек. 2014 г.). В 2 ч.- М. : Медина, 2015. - Ч. 1. -378 с. ; Ч. 2. -408 с.

4. Саматова, Ч. Х. Имперская власть и татарская школа во второй половине XIX - начале XX века (по материалам Казанского учебного округа) / Ч. Х. Саматова. - Казань: Татар. кн. изд-во, 2013. -239 с.

5. Сенюткин, С. Б. История татар Нижегородского Поволжья с последней трети XVI до начала $\mathrm{XX}$ вв. (историческая судьба мишарей Нижегородского края) / С. Б. Сенюткин. - М. ; Нижний Новгород : Медина, 2009. $-476 \mathrm{c}$.

6. Сенюткина, О. Н. Детство и юность Х. Фаизханова / О. Н. Сенюткина // Фаизхановские чтения. -2006 . - № 3. - С. 18-23.

7. Сенюткина, О. Н. Конфессиональное многообразие Нижегородского Поволжья под влиянием государственной управленческой политики / О. Н. Сенюткина // Исповеди в зеркале: межконфессиональные отношения в центре Евразии (на примере ВолгоУральского региона - XVIII-XXI вв.). - Нижний Новгород : Изд-во НГЛУ, 2012. - С. 40-62.

8. Труды Хусаина Фаизханова // Хусаин Фаизхан - классик татарского просвещения, истории и педагогики. - Москва ; Нижний Новгород : Медина, 2014. - С. 164-319.

9. Усманов, М. А. Заветная мечта Хусаина Фаизханова. Повесть о жизни и деятельности / М. А. Усманов. - Казань : Тат. кн. изд-во, 1980. -223с.

10. Фаизханов, Х. Реформа медресе / Х. Фаизханов ; пер. со старотат. И. Ф. Гимадеев ; под ред. Д. В. Мухетдинова. - Нижний Новгород : Медина, 2007.- $36 \mathrm{c}$.

11. Хабутдинов, А. Ю. Хусаин Фаизханов: у истоков общественного движения мусульман-татар / А. Ю. Хабутдинов, Д. В. Мухетдинов, О. Н. Сенюткина. - Нижний Новгород : Махинур, 2006. - 96 с.

12. Хусаин Фаизханов. Жизнь и наследие: историко-документальный сборник / пер. со старотат. А. М. Ахунова, И. Ф. Гимадеева; сост. и отв. ред. Д. В. Мухетдинов. - Нижний Новгород : Медина, 2008. -152 c. 
13. Черновская, В. В. Хусаин Фаизханов и мусульманские просветители в России (1858-1860 гг.) / В. В. Черновская // Фаизхановские чтения : материалы пятой Ежегод. науч.-практ. конф. «Фаизхановские чтения».-М. : Медина, 2009. -296 c.

\section{REFERENCES}

1. Mukhetdinov D.V. Husain Faizhanov klassik tatarkogo prosveshcheniya, istorii $i$ pedagogiki [Hussain Faizhanov- the Classicist of Tatar Education, History and Pedagogy]. Moscow; Nizhny Novgorod, Medina Publ., 2014. 340 p.

2. Plekhanov G.V. K voprosu o roli lichnosti v istorii [On the Role of an Individual in History]. Izbrannye filosofskie proizvedeniya. V 5 t. T. 2 [Selected Philosophical Works. In 5 vols. Vol. 2]. Moscow, Gosudarstvennoe izd-vo politicheskoy literatury, 1956.824 p.

3. Reformy obrazovaniya musulman Evrazii ot Khusaina Faizkhanova do Ismaila Gasprinskogo: istoricheskiy opyt i sovremennaya aktualnost [Muslim Educational Reforms in Eurasia from Hussain Faizhanov to Ismail Gasprinskiy: Historical Experience and Contemporary Relevance]. Materialy Yubileynoy $X$ Vserossiyskoy nauchno-prakticheskoy konferentsii $s$ mezhdunarodnym uchastiem "Faizkhanovskie chteniya” (Moskva, 12 dekabrya 2014 g.). V 2-kh ch. [Proceedings of the Jubilee 10th All-Russian Research and Practice Conference Involving Foreign Participants "Faizhanov's Readings" (Moscow, December 12, 2014). In 2 Parts]. Moscow, Medina Publ., 2015, Part 1. 378 p.; Part 2. 408 p.

4. Samatova Ch.Kh. Imperskaya vlast $i$ tatarskaya shkola vo vtoroy polovine XIX-nachale XX veka (po materialam Kazanskogo uchebnogo okruga) [Imperial Power and Tatar School in the Second Half of the 19th - Beginning of the 20th Century]. Kazan, Tatarskoe knizhnoe izd-vo, 2013.239 p.

5. Senyutkin S.B. Istoriya tatar Nizhegorodskogo Povolzhya s posledney treti XVI do nachala XX vv. (Istoricheskaya sudba misharey Nizhegorodskogo kraya) [The History of the Tatars of Nizhny Novgorod Volga Region from the Last Third of the 16th to the Beginning of the 20th Centures (The Historical Fate of the Michars of the Nizhny Novgorod Region)]. Moscow; Nizhny Novgorod, Medina Publ., 2009. 476 p.

6. Senyutkina O.N. Detstvo $i$ yunost H. Faizhanova [The Childhood and the Youth of H. Faizhanov]. Faizhanovskie chteniya [Faizhanov's Readings]. Nizhny Novgorod, 2006, no. 3, pp.18-23.

7. Senyutkina O.N. Konfessionalnoe mnogoobrazie Nizhegorodskogo Povolzhya pod vliyaniem gosudarstvennoy upravlencheskoy politiki [Confessional Variety of Nizhny Novrogod Volga Region Under the Influence of State Administrative Politics]. Ispovedi v zerkale: mezhkonfessionalnye otnosheniya $v$ tsentre Evrazii (na primere Volgo-Uralskogo regiona - XVIII-XXI vv.) [Confessions in the Mirror: Interconfessional Relations in Central Eurasia (on the Example of Volgo-Uralsk Region - 18th-21st Centuries)]. Nizhny Novgorod, Izd-vo NGLU, 2012, pp. 40-62.

8. Trudy Husaina Faizhanova [Hussain Faizhanov's Works]. Hussain Faizhan - klassik tatarskogo prosveshcheniya, istorii i pedagogiki [Hussain Faizhanov - Classicist of Tatar Education, History and Pedagogy]. Moscow; Nizhny Novgorod, Medina Publ., 2014, pp.164-319.

9. Usmanov M.A. Zavetnaya mechta Husaina Faizhanova [Cherished Dream of Husain Faizhanov]. Kazan, Tatarskoe knizhnoe izd-vo, 1980. 223 p.

10. Faizhanov H. Reforma medrese [Madrasah Reform]. Nizhny Novgorod, Medina Publ., 2007. 36 p.

11. Khabutdinov A.Yu., Mukhetdinov D.V., Senyutkina O.N. Hussain Faizhanov: u istokov obshchestvennogo dvizheniya musulman-tatar [Hussain Faizhanov: at the Origin of Social Movement of Muslim Tatars]. Nizhny Novgorod, Makhinur Publ., 2006. 96 p.

12. Hussain Faizhanov. Zhizn i nasledie: istorikodokumentalnyy sbornik [Life and Heritage: Historical Documentary Collection]. Nizhny Novgorod, Medina Publ., 2008. 152 p.

13. Chernovskaya V.V. Hussain Faizhanov i musulmanskie prosvetiteli v Rossii (1858-1860 gg.) [Hussain Faizhanov and Muslim Educators in Russia (1858-1860)]. Materialy pyatoy ezhegodnoy nauchnoprakticheskoy konferentsii «Faizkhanovskie chteniya» [Proceedings of the 5th Annual Research and Practice Conference "Faizhanov's Readings"]. Moscow, Medina Publ., 2009. 296 p. 